Pacific Journal of Mathematics

A FACTORABLE BANACH ALGEBRA WITHOUT BOUNDED approximaTE UN TT 


\title{
A FACTORABLE BANACH ALGEBRA WITHOUT BOUNDED APPROXIMATE UNIT
}

\author{
William L. PASChKE
}

This note gives an example of a Banach algebra all of whose elements can be factored, but which has no bounded left or right approximate unit.

We first state P. J. Cohen's factorization theorem for Banach algebras and the generalization thereof obtained by E. Hewitt and, independently, P. C. Curtis and A. Figà-Talamanca. (See 32.22 and 32.26 of [1].)

Theorem 1. Let $A$ be a Banach algebra with bounded left approximate unit. Then for each $z \in A$ and $\delta>0$, there exist elements $x, y \in A$ such that:
(i) $z=x y$,
(ii) $y \in \overline{A z}$,
(iii) $\|z-y\|<\delta$.

Theorem 2. Let $A$ be a Banach algebra with left approximate unit bounded in norm by $D$, and $\left(L,\|\cdot\|_{L}\right)$ a left Banach A-module. Let $z$ belong to the closed linear span of $A \cdot L$. Then for every $\delta>0$ we can find $a \in A, y \in L$ such that:

(i) $z=a \cdot y$,

(ii) $\|a\| \leqq D$,

(iii) $y \in \overline{A \cdot z}$,

(iv) $\|y-z\|_{L} \leqq \delta$.

In particular, $A \cdot L$ is a closed linear subspace of $L$.

Theorem 1 may be abbreviated to read: "If a Banach algebra has either a bounded left or right approximate unit, then each of its elements can be factored." The purpose of this note is to show by example that the converse of this abbreviated version of Cohen's result is false. We remark here that partial converses to Theorems 1 and 2, employing suitable "factorability" hypotheses, have been obtained in [2], [3], and [4].

The general idea of our construction is set forth in the following lemma.

Lemma. Let $B$ be a Banach algebra with 1 , and suppose $a \in B$ satisfies:

(i) $\|a\|=1$, 
(ii) for $b \in B, a b=0$ implies $b=0$,

(iii) $a B$ is not closed in $B$,

(iv) $b_{1} a b_{2}=1$ for some $b_{1}, b_{2} \in B$.

Let $A=a B$. Then $A$ can be renormed to be a Banach algebra each of whose elements can be factored, but which has no bounded right or left approximate unit.

Proof. Define $\|\cdot\|_{0}$ on $A$ by $\|a b\|_{0}=\|b\|$ for $b \in B$. This is a well-defined Banach space norm on $A$ by (ii). For $b, c \in B$, we have $\|(a b)(a c)\|_{0}=\|b a c\| \leqq\|b\|\|c\|=\|a b\|_{0}\|a c\|_{0}$, so $\|\cdot\|_{0}$ is an algebra norm on $A$ as well. The algebra $B$ is naturally a left $A$-module, and in fact a Banach $A$-module, since for $b, c \in B$, $\|(a b) c\| \leqq\|b\|$ $\|c\|=\|a b\|_{0}\|c\|$. By (iii), $A \cdot B=a B$ is not a closed subspace of $B$; we conclude from Theorem 2 that $A$ has no bounded left approximate unit. Suppose that $A$ has a right approximate unit (bounded or otherwise) $\left\{a e_{\alpha}\right\}$. Then in particular $\lim _{\alpha}\left\|a e_{\alpha}-1\right\|=\lim _{\alpha}\left\|a^{2} e_{\alpha}-a\right\|_{0}=0$, showing that $\overline{a B}=B$ and hence $a B=B$, since a Banach algebra with 1 can have no dense proper right or left ideals. This contradicts (iii), so $A$ has no right approximate unit. Finally, we note that (iv) allows us to factor any element $a b$ of $A$ as $a b=\left(a b b_{1}\right)\left(a b_{2}\right)$.

We now give an example of a situation in which the hypotheses of the lemma are satisfied. Let $l^{2}$ denote the space of all absolutely square-summable sequences of complex numbers, normed in the usual way, and let $\mathfrak{B}$ be the Banach algebra of all bounded linear operators on $l^{2}$. Let $\left\{\lambda_{n}\right\}$ be a sequence of real numbers with $1 \geqq \lambda_{n}>0$ for $n=1,2, \cdots$, and $\lim _{n} \lambda_{n}=0$. Letting $x_{j}$ denote the $j$ th coordinate of the element $x \in l^{2}$, we define operators $T, V \in \mathfrak{B}$ by

$$
\begin{aligned}
& T x=\left(x_{1}, \lambda_{1} x_{2}, x_{3}, \lambda_{2} x_{4}, x_{5}, \cdots\right) \\
& V x=\left(x_{1}, 0, x_{2}, 0, x_{3}, 0, \cdots\right)
\end{aligned}
$$

Clearly $\|T\|=1$ and $T$ is one-to-one, so for $W \in \mathfrak{B}, T W=0$ implies $W=0$. For $n=1,2, \cdots$, let $E_{n} \in \mathfrak{B}$ be the orthogonal projection on the $(2 n)$ th coordinate. We have $\lim _{n}\left\|T E_{n}\right\|=\lim _{n} \lambda_{n}=0$. Since $\left\|E_{n}\right\|=1$ for each $n$, we see from the open mapping theorem that $T \mathfrak{B}$ cannot be closed in $\mathfrak{B}$. A direct computation shows that $V^{*} T V=I$. We may now invoke the lemma (with $V^{*}, T$, and $V$ playing the roles of $b_{1}, a$, and $b_{2}$, respectively) to see that $T \mathfrak{B}$, appropriately normed, is a Banach algebra all of whose elements can be factored, but which has no bounded left or right approximate unit.

If we set $X=T\left(l^{2}\right)$, then it is clear that the natural representation of $T \mathfrak{B}$ on $X$ is irreducible. $X$ is dense in $l^{2}$, and from this it follows that said representation is faithful, i.e., $T \mathfrak{B}$ is a primitive algebra. One also checks that the map $T W \rightarrow T\left(W^{*}\right)$ is an (isometric) 
involution on $T \mathfrak{B B}$. The example which we have introduced is therefore not particularly pathological from an algebraic standpoint.

The author wishes to thank Professor Kenneth A. Ross for suggesting the problem of deciding whether or not an algebraically factorable Banach algebra must have a bounded approximate unit.

\section{REFERENCES}

1. E. Hewitt and K. A. Ross, Abstract Harmonic Analysis II, Springer-Verlag, New York, 1970.

2. T.-s. Liu, A. van Rooij, and J.-k. Wang, Bounded approximate identities in ideals of commutative group algebras, to appear.

3. F. D. Sentilles and D. C. Taylor, Factorization in Banach algebras and the general strict topology, Trans. Amer. Math. Soc., 142 (1969), 141-152.

4. D. C. Taylor, A characterization of Banach algebras with approximate unit, Bull. Amer. Math. Soc., 74 no. 4, (1968), 761-766.

Received March 30, 1972.

UNIVERSITY OF OREGON

Current address: University of Kansas 



\section{PACIFIC JOURNAL OF MATHEMATICS}

\section{EDITORS}

D. Gilbarg and J. Milgram Stanford University

Stanford, California 94305

R. A. Beaumont

University of Washington

Seattle, Washington 98105
J. DugundJI

Department of Mathematics

University of Southern California

Los Angeles, California 90007

RICHARD ARENS

University of California

Los Angeles, California 90024

ASSOCIATE EDITORS
E. F. BECKENBACH
B. H. NeumanN
F. WOLF
K. YoSHIDA

\section{SUPPORTING INSTITUTIONS}

UNIVERSITY OF BRITISH COLUMBIA

CALIFORNIA INSTITUTE OF TECHNOLOGY

UNIVERSITY OF CALIFORNIA

MONTANA STATE UNIVERSITY

UNIVERSITY OF NEVADA

NEW MEXICO STATE UNIVERSITY

OREGON STATE UNIVERSITY

UNIVERSITY OF OREGON

OSAKA UNIVERSITY
UNIVERSITY OF SOUTHERN CALIFORNIA

STANFORD UNIVERSITY

UNIVERSITY OF TOKYO

UNIVERSITY OF UTAH

WASHINGTON STATE UNIVERSITY

UNIVERSITY OF WASHINGTON

$\stackrel{*}{*} \stackrel{*}{*} \stackrel{*}{*}$ AMERICAN MATHEMATICAL SOCIETY

NAVAL WEAPONS CENTER 


\section{Pacific Journal of Mathematics}

\section{Vol. 46, No. $1 \quad$ November, 1973}

Allan Francis Abrahamse, Uniform integrability of derivatives on $\sigma$-lattices .......................................... 1

Ronald Alter and K. K. Kubota, The diophantine equation $x^{2}+D=p^{n} \ldots \ldots \quad 11$

Grahame Bennett, Some inclusion theorems for sequence spaces .......... 17

William Cutler, On extending isotopies ........................ 31

Robert Jay Daverman, Factored codimension one cells in Euclidean

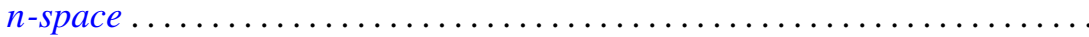

Patrick Barry Eberlein and Barrett O’Neill, Visibility manifolds ............ 45

M. Edelstein, Concerning dentability .......................... 111

Edward Graham Evans, Jr., Krull-Schmidt and cancellation over local

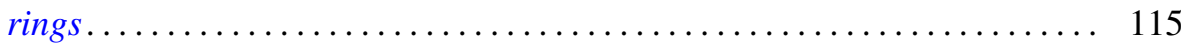

C. D. Feustel, A generalization of Kneser's conjecture ................ 123

Avner Friedman, Uniqueness for the Cauchy problem for degenerate parabolic equations .......................................... 131

David Golber, The cohomological description of a torus action ............ 149

Alain Goullet de Rugy, Un théorème du genre "Andô-Edwards" pour les

Fréchet ordonnés normaux..............................

Louise Hay, The class of recursively enumerable subsets of a recursively enumerable set ........................................

John Paul Helm, Albert Ronald da Silva Meyer and Paul Ruel Young, On orders of translations and enumerations...

Julien O. Hennefeld, A decomposition for $B(X)^{*}$ and unique Hahn-Banach

extensions

Gordon G. Johnson, Moment sequences in Hilbert space .

Thomas Rollin Kramer, A note on countably subparacompact spaces ...

Yves A. Lequain, Differential simplicity and extensions of a derivation ....

Peter Lorimer, A property of the groups Aut $\mathrm{PU}\left(3, q^{2}\right) \ldots$

225

Yasou Matsugu, The Levi problem for a product manifold.

231

John M.F. O'Connell, Real parts of uniform algebras ......

William Lindall Paschke, A factorable Banach algebra without bounded

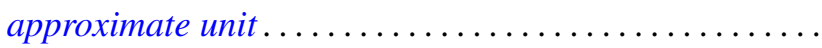

Ronald Joel Rudman, On the fundamental unit of a purely cubic field ....

Tsuan Wu Ting, Torsional rigidities in the elastic-plastic torsion of simply connected cylindrical bars .........................

Philip C. Tonne, Matrix representations for linear transformations on analytic sequences...................................

Jung-Hsien Tsai, On E-compact spaces and generalizations of perfect

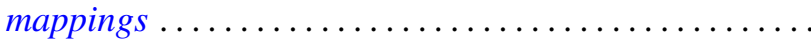

Alfons Van Daele, The upper envelope of invariant functionals majorized by an invariant weight. .. 